Primary care paediatrics and child health

\section{Paediatrics in primary care}

\section{T Waterston, N Mann}

\section{A new series}

ncreasingly the future organisation of paediatrics at secondary level, the place of first referral, depends greatly on the organisation and quality of care at primary level. The ability of paediatricians to influence primary child health care is limited at present to advocacy and training, but recently some have been expressing the view that we in the UK should follow US and European practice in developing the concept of primary care paediatricians.
Whilst the Court Report in 1976 ("Fit for the Future") introduced the concept of the GP paediatrician, this was intended to be a GP with additional training rather than a trained paediatrician, as we know it today.

Clearly there are many potential benefits of paediatricians working in primary care to provide specialist care and manage chronic conditions. Some also argue the case for management of acute illness at this level. However there may be potential pitfalls; not least whether these concepts fit with current ideas of service planning by general practitioners and health service managers.

Hence we have asked a range of experts with specific expertise to describe their perspective on the future of paediatric primary care and the interface with secondary care, as well as seeking the perspective of the RCPCH. These issues are for debate and we encourage readers to contribute their views through a rapid response.

Arch Dis Child 2004;89:112.

doi: 10.1136/adc. 2003.046235

[......................

Authors' affiliations

T Waterston, Guest editor

N Mann, Commissioning editor, $A D C$

Correspondence to: $\operatorname{Dr} N$ Mann, Dept of Paediatrics, Royal Berkshire Hospital, London Road, Reading RGI 5AN, UK; npmann2@aol.com
Primary care paediatrics and child health

\section{Out of hours care}

\section{A Craft}

\section{A personal view}

l: is now just over 25 years since Donald Court reviewed paediatric services in the UK. The only major recommendation that was not eventually implemented was the concept of a general practitioner paediatrician (GPP). ${ }^{1}$ Court recognised the importance of strengthening the care of children wherever they might be: in the hospital, community, or in general practice. Recent years have seen an integration of hospital and community paediatric services which has resulted in better care, especially for vulnerable and disabled children. The government's new Green Paper, ${ }^{2}$ which puts an emphasis on integration of education, social care, and aspects of health, does potentially threaten to destabilise the integration of paediatric services. We must be aware of the danger and find a way of working across boundaries. The green paper was driven by the horror of the murder of Victoria Climbié and we must all try to ensure that in a further 25 years we are still saying that we have not learned the lessons that date back to the tragedy of Maria Colwell in the 1970s. Paediatric services are inevitably changing and child protection is just one of the driving forces. The implementation of the European Working Time Directive for trainee doctors in 2004 changes in morbidity, greater public expectation from parents, and the falling birth rate are just some of the issues which force us to rethink how, where, and by whom paediatric services should be delivered.

The most obvious change in recent years has been the vastly increased numbers of children who attend hospital for emergency assessment when they are perceived by their parents to be ill. Many can be seen and immediately reassured that there is nothing seriously amiss, while the majority of the rest can be sent home after a short period of observation. There appears to have been a substantial shift of work from general practice to hospital, although this is difficult to quantify. The greater number of children attending hospital could genuinely be due to greater parental anxiety. But it is also fuelled by difficulty in access to out-of-hours general practice care and by NHS Direct. Most such care is now provided through cooperatives that are staffed by GPs working shifts of six to eight hours. This makes it difficult for a GP to see a potentially sick child and to review them again within the same shift. There is an understandable reluctance to hand on to the next shift so that the safest thing to do is to send the child up to hospital where a short period of observation will be possible. The new GP contract which will allow them to opt out of night-time cover is likely to increase the flow of such patients. We must accept that this change in pattern of referral is inevitable and unlikely to be reversed, at least in the medium term. Services must be designed and staffed to cope with this workload.

The vast majority of children who are perceived to be ill have always been seen in general practice. They form a substantial part of any GP's workload. Indeed general practice is a fundamentally important part of the NHS in the UK. Over $99 \%$ of the population are registered with a family doctor. Ninety five per cent of consultations in the NHS are conducted in primary care, and $80 \%$ are dealt with by primary care teams with no involvement of hospital specialists. ${ }^{3}$ During the day, sick children will continue to be cared for by GPs and this is to be encouraged and supported. However, out-of-hours the situation is different. Although general practice will have a role, the number who are proposing to opt out of night-time cover makes it likely that a different and appropriately funded situation needs to be found. 
The basic philosophy must be that services are built around the needs of the child, not of the professionals. The best possible care must be provided as close to a child's home as possible.

The ideas set out in Strengthening the care of children in the community ${ }^{4}$ and "Paediatrics 2010" suggest we should be moving towards a model of locally delivered services with rapid access when necessary to whatever care is required.

I envisage each locality having an emergency assessment unit. This is likely to be based in a hospital, within the paediatric department or next to A\&E (ideally close to both). The hospital itself may not have overnight paediatric inpatients. It will be staffed during daytime and evening hours by trained staff. These may be a combination of doctors and nurses. Such a facility would be ideal for training but would not rely on trainees to provide the service. When the facility is closed outof-hours the local public must be educated to try and adjust their time of attendance. There are very few children who suddenly become ill out-of-hours. However a mechanism to deal with such sick children needs to be in place.

The public has been led to expect 24 hour service, whether it be for supermarkets or healthcare. These attitudes must change if we are to staff the health service adequately and economically. We may be able to provide a "Tesco Extra" service in some areas, but others will need to be served by "Tesco Metro"style facilities. Perhaps "Extra" (24 hours) and "Metro" ( 8 'til late) would be concepts that the public would understand!

Who would staff such a facility? Nurse practitioners or nurse consultants could be involved as the frontline, with consultant back up either on-site or at least rapidly available. We know that a third year paediatric registrar can handle the majority of acute presentations without any back up. The Department of Health's proposals for shortening the minimum length of training ${ }^{6}$ for award of a CCT entry onto the Specialist Register and ability to apply for a consultant post would suggest that we might modify our training so that by the end of, say, five years post registrate training, we could produce "consultant emergency paediatricians". An alternative for staffing these emergency assessment units would be to involve experienced general practitioners. There are an increasing number of GPs developing a special interest, known as GPuSI. ${ }^{7}$ With appropriate interest and training there is no reason why they should not be involved as full members of such a team looking after the emergency unit.

Primary Care Trusts are ultimately responsible for out-of-hours primary care, so they might be persuaded to divert funds to appropriately staff an emergency assessment unit.
Emergency assessment is at the hinterland between primary and secondary care. The work perhaps needs to be undertaken by a mixture of those currently designated as primary or secondary care staff. They could both do the job and enhance local services for children.

Perhaps the time for the court's GPP has arrived at last?

Arch Dis Child 2004;89:112-113.

doi: $10.1136 /$ adc. 2003.040642

Correspondence to: Dr A Craft, Dept of Child Health, Royal Victoria Infirmary, Newcastle upon Tyne, UK; a.w.craft@nd.ac.uk

\section{REFERENCES}

1 Court SDM. Fit for the future. The report of the committee on child health services. London: HMSO, 1976

2 Department for Education and Skills. Every child matters. London: The Stationery Office, 2003.

3 Nuffield Trust. Measuring General Practice. Nuffield Trust, 2003.

4 Royal College of Paediatrics and Child Health Strengthening the care of children in the community. London: RCPCH, 2002.

5 Royal College of Paediatrics and Child Health. The next ten years: educating paediatricians for new roles in the 21 st century. London: $\mathrm{RCPCH}$, 2002.

6 Department of Health. Modernising medical careers: the response of the four UK health ministers to the consultation on "Unfinished Business: Proposals for Reform of the Senior House Officer Grade". London: Department of Health, 2003

7 Department of Health and Royal College of General Practitioners. Implementing a scheme for general practitioners with special interests. $\mathrm{DH}$, 2002 .

\section{The future of primary care paediatrics and child health}

\section{E Peile}

\section{Patterns, trends, and influences in child health}

don't anticipate tomorrow's children will be very different from today's. More extreme pre-term survivors, maybe; growing taller perhaps, and certainly more likely to be obese, these children are likely to be subjected to ever increasing pressures to perform in their schools and conform in their streets. There is something timeless about childhood, but child healthcare is as subject to the fads and fashions of the era as is the nurturing process. In planning primary care paediatrics, we need to look further than the child. We need to think about parents and parenting, about societal influences, and about workforce issues.

\section{GENERALIST AND SPECIALIST}

Nearly 30 years ago, Donald Court, whose report drew heavily on the wishes of parents, raised the notion of the "GP paediatrician". ${ }^{1}$ The general practitioner with special clinical interests (GPuSI) has resurfaced in the NHS Plan. ${ }^{2}$ Already as many as 4000 general practitioners (GPs) specialise, ${ }^{3}$ but rarely in paediatrics. This is not for lack of GPs with expertise or interest in paediatrics; the reason is that
Primary Care Trusts have prioritised identifying GPuSIs who are trained and skilled in procedures such as endoscopy, or able to help reduce costs or waiting times in specialities such as ENT, or musculoskeletal medicine. Experience in other specialties has shown that GPuSIs may become valued either by taking formal or informal referrals from less experienced generalist colleagues, or by leading and developing a local service. ${ }^{4}$ Quality assurance, ${ }^{5}$ and the need to certify the necessary competencies ${ }^{6}$ are being addressed. Issues remain around how a paediatric GPuSI may best fit into local contexts; $;^{7}$ new appointments should, I believe, only be made to satisfy a case of need in the locality.

\section{FOR RICHER, FOR POORER; IN SICKNESS AND IN HEALTH}

Over the past 20 years, GPs have seen enormous changes in parental behaviour, both in respect of the sick child and the well one. The pattern remains one of significantly higher consultation rates in children from socially disadvantaged families for minor to serious 
Examples of local cases of need for a paediatric GPuSI appointment

- Providing a satellite service for a group of practices in a remote location, to reduce the need for children to travel to specialist centres

- Augmenting a community paediatric service where there are skill shortages

- Undertaking practice based follow up of specific chronic conditions to reduce attendance at hospital clinics

- Initiating new direct access primary paediatric services targeted at certain population groups (for example, homeless people, travellers, and asylum seekers)

- Enhancing acute services for minor paediatric conditions (daytime or outof-hours)

illnesses with correspondingly higher home visiting rates. The concern is that these families also have lower rates of child health and preventive consultations. ${ }^{8}$ The trend is for all social classes to call on primary care earlier in the evolution of a child's illness. Anecdotally at least, there is a domino effect, whereby more risk averse parents, fearing to nurse their feverish child at home, pass their anxiety on to GPs. Their higher call rate results in higher demands on hospitals, many of which have responded by increasing facilities for short term observation rather than inpatient admission. The benefit of early hospital contact is debated. As hospital admission rates for asthma in young children have increased, the mortality rates have declined, ${ }^{9}$ but case fatality rates for meningitis have shown little change. ${ }^{10}$ The Commission for Health Improvement (CHI) cites "enhanced primary care" as a factor in reducing emergency admissions to hospital of children with lower respiratory infections, which is an indicator of service quality. ${ }^{11}$

\section{OUT-OF-HOURS SERVICES}

Although nurse triage as part of an oncall service has been shown to be safe, efficient, and effective, ${ }^{12}$ NHS Direct has done little to reduce the calls on general practitioner services. ${ }^{13}{ }^{14}$ Many, if not most, GPs will opt out of out-of hours services from April 2004, ${ }^{15}$ but there is little indication, as yet, of the nature of the services that Primary Care Trusts will organise to replace doctor's cooperatives. Commercial deputising may increase, as may the (cheaper) use of nurse led services. Will these involve specialist teams? As the generalist retreats to daytime service, could nighttime calls about sick children be triaged to paediatric trained nurses and doctors? I see another potential role for the GPSCI here, linking closely with hospital colleagues.

\section{LOCUS OF CARE}

One thing seems likely: cost pressures will accelerate the trend for fewer home visits. If parents are expected to bring a sick child to a health centre or on-call base, why not to one with child observation facilities? An example of potential benefits is that better detection of urinary tract infections might result from better facilities to collect samples from febrile infants.

In paediatrics, as in other specialties, gatekeeping is cited as part of the role of the general practitioner, but yet when the Americans introduced primary care gatekeeping in the delivery of services for some children with chronic conditions, there was a reduction in visits to specialists, but also, worryingly, less contact with primary care doctors, who were thus unable to provide the care previously supplied by specialists. ${ }^{16}$ Other European countries base their systems around primary care paediatricians. ${ }^{17}$ It may be best to let parents choose whom to consult!

Community paediatricians, hospital specialists (both medical and nursing), GPuSIs, and community paediatric nurses could between them manage in the community much of the present workload of hospital outpatient clinics. Primary care collaborations are increasing; at the Personal Medical Services (PMS) project where I have been working, the records for 26000 patients were available on-line at any of three surgeries. It often helps if clinicians, reviewing the child with cystic fibrosis, growth problems, or diabetes, can see and contribute to the primary care records, prescribing on the same database, and making management suggestions that all doctors and nurses will be able to see at future contacts. There is a caveat, as studies of hospital outreach clinics in other specialities have shown that, although popular and effective, they may incur higher NHS costs. ${ }^{18}$

\section{PREVENTATIVE CARE}

Nowadays, parents of well children, deliberating about immunisation decisions, are perhaps less influenced than former generations by the views of family practitioners and health visitors, and perhaps more influenced by media and net searching. The credibility of health visitors and GPs depends on upto-date knowledge of the paediatric evidence base, and professionals need to be expert at interpreting the information for the particular parent and child. Modern childcare arrangements have encouraged more parents to work full time, and if we really want to reach parents, we will have to balance reduced out-of-hours responsibilities with increased availability for preventative healthcare at extended practice hours.

\section{NEW WAYS OF LEARNING FOR NEW WAYS OF WORKING}

The implications of future gazing are important for learning. As the Children Care Group Workforce Team rethinks training in the light of current changes in NHS planning, they have appropriately prioritised communication skills and leadership. ${ }^{19}$ Enhanced skills in evidence based child care, and satisfactory ways of updating about rare but important conditions in primary $\operatorname{care}^{20}$ are other priorities. If clinicians are to become comfortable disrespecting the boundaries between primary and secondary care, ${ }^{21}$ between hospital and community, and between different nursing and medical backgrounds, they need to spend time learning with, from, and about each other. Effective interprofessional learning is crucial. Primary care paediatricians will probably gain more from contextual learning in the community, than from extending time in the hospital setting.

Arch Dis Child 2004;89:113-115. doi: 10.1136/adc.2003.040741

Correspondence to: Professor E Peile, Director of Medical Education, The University of Warwick, Coventry CV4 7AL, UK; Ed.Peile@warwick.ac.uk

\section{REFERENCES}

1 Court SDM (Chair). Fit for the future: The Report of the Committee on Child Health Services. London: HMSO, 1976

2 Secretary of State for Health. The NHS Plan: a plan for investment, a plan for reform. London: Stationery Office, 2000.

3 Jones R, Bartholomew J. General practitioners with special clinical interests: a cross-sectional survey. Br J Gen Pract 2002;52:833-4.

4 Williams S, Ryan D, Price D, et al. General practitioners with a special clinical interest: a model for improving respiratory disease management. Br J Gen Pract 2002;52:838-43.

5 Royal College of General Practitioners. General practitioners with special clinical interests. London: RCGP, 2001.

6 Royal College of Paediatrics and Child Health. Competencies of the primary health paediatrician. Reference paper for Diploma of Child Health Examinations Board. London: RCPCH, 2003. 
7 Rosen R, Stevens R, Jones R, General practitioners with special clinical interests. BMJ2003;327:460-2.

8 Saxena S, Majeed A, Jones M. Socioeconomic differences in childhood consultation rates in general practice in England and Wales: prospective cohort study. BMJ 1999:318:642-6.

9 Lung and Asthma Information Agency. Trends in hospital admissions and deaths from asthma. London: St Georges Hospital Medical School 2002.

10 Goldacre M, Roberts E, Yeates D. Case fatality rates for meningococcal disease in an English population, 1963-98: database study. BMJ 2003:327:596-7.

11 Commission for Health Improvement. Rating the NHS: 2002/3 NHS performance ratings. http:// www.chi.nhs.uk/eng/ratings/2003/. Accessed 18 October 2003
12 Lattimer V, George S, Thompson F. Safety and effectiveness of nurse telephone consultation in out of hours primary care: randomised controlled trial. BMJ 1998;317:1054-9.

13 Munro J, Nicholl J, O'Cathain A, et al. Impact of NHS Direct on demand for immediate care: observational study, BMJ 2000:321:150-3.

14 Chapman R, Smith GE, Warburton F, et al. Impact of NHS Direct on general practice consultations during the winter of 1999-2000: analysis of routinely collected data. $B M$ 2002;325: 1397-8.

15 NHS Confederation. Out of hours services under the new GP contract. http:// www.nhsconfed.webhoster.co.uk/docs/ 4outofhourse.pdf. Accessed 18 October 2003.

16 Ferris TG, Perrin JM, Manganello JA, et al. Switching to gatekeeping: changes in expenditures and utilisation for children Pediatrics 2001:108:283-90.

17 Murphy JFA. The role of gatekeeping as a tool in healthcare delivery. Ir Med J 2001;94:292.

18 Bowling A, Bond M. A national evaluation of specialists' clinics in primary care settings. $B r J G e n$ Pract 2001:51:264-9.

19 Children Care Group Workforce Team. A general update on workforce planning and development in relation to children and maternity services. http://www.doh.gov.uk/cgwt. Accessed 18 October 2003.

20 Peile E. Commentary: learning to stay vigilant about conditions that are rare but important. $B M$ 2003:327:919.

21 Pringle $M$. Please mind the gap: addressing the divide between primary and secondary care. Clin Med 2001;1:172-4.

\section{The future for child healthcare provision within general practice}

\section{Sowden}

\section{Children's health remains an integral element of general practice}

n common with other healthcare services in the United Kingdom, general practice (GP) is faced with an ever increasing pace of change which is best highlighted by the implementation and implications of the new GP (General Medical Services, GMS) contract.

In the light of these changes, the increasing expectations of parents, the escalating presentation of disease, ill health, and mental health issues amongst children, it seems reasonable to ponder the future for child health care provision within GP.

It seems reasonable to expect there to be a comprehensive child health service in GP because the frequency of presentation of acute illness and the ongoing management of certain key chronic diseases are likely to be beyond the capacity of any rational existing and future secondary care/mental health and community paediatric service plan. The Wanless report ${ }^{1}$ highlights the inadequacy of the doctor population in the United Kingdom for the foreseeable future. It is therefore remarkably unlikely, even with the Children's National Service Framework (NSF), that the number of paediatricians will expand to any significant extent at the expense of other medical or surgical disciplines where performance targets remain.

The implementation of the European Working Time Directive (EWTD) will have a major impact on the organisation and provision of paediatric services, as will the government's aspirations for a consultant delivered service. ${ }^{23}$

I would suggest these will prove significant enough challenges without expanding the work of paediatricians into the initial presentation of child illness in primary care.

From a GP perspective, there is also the considerable importance of maintaining a holistic and family based approach. Children remain an integral part of families in the United Kingdom, and cannot be seen as an isolated population. While it will be difficult to maintain historic levels of continuity of doctor delivered care, general practice has a long history of innovative team based approaches to care ${ }^{4}$ and through this route current services should be both maintained and refined. The key role of the general practitioner as NHS gatekeeper and manager of risk needs careful evaluation before major changes are implemented and these roles potentially lost.

Primary care paediatricians could, however, be seen as a logical extension of the government's patient choice agenda. If the evidence base were to support this development there could be little objection. However, currently we have little or no evidence that paediatricians based in primary care within UK health services are even as effective as general practitioners. Effective GP is about the synergy of physical, psychological, and social care within the framework of caring for families over time. Artificial separation of children's health care runs contrary to these principles, and risks the sidelining of child health care issues from mainstream primary care. A risk that already exists with the disappointing lack of emphasis on child health within the new GMS contract.

If we are to accept the premise that there has to be an integral child health care service in GP, then how it will be delivered, and how relevant staff might be trained becomes the area for most productive debate.

This article is too short to consider the critical roles of all relevant non-medical professionals but the future will clearly be multiprofessional and team based. The structure and leadership of these teams will vary across England in line with differences in the population and the available professional workforce. There will be little future for doctors unable or unwilling to work effectively in such an environment.

The following concentrates on a future model for training general practitioners and how child health services might be delivered in primary care organisations (PCOs).

While much has been done to refine general practice vocational training, since its formal inception in 1979, the present arrangements ensure that only one third of training takes place in GP. Therefore, both the context and the control of the educational experience is out with the control of the discipline of GP and its educators. GP is the only recognised specialty for which this is the case.

Unfinished business ${ }^{5}$ and Modernising medical careers ${ }^{6}$ provide an opportunity to radically change the arrangements for vocational education for general practice. It may allow the implementation of a three year programme based in GP with planned release to specialist hospital and community settings. This will allow all future GPs to be trained in relevant child health practice, in particular 
the recognition of acute illness, and experience of working in extended teams managing children with complex and special needs. It will allow some GPs to develop special interests in child health who will provide specialist services within PCOs. Such services must form part of a comprehensive and collaborative local arrangement with community and hospital sectors. To this end care must be taken in defining the roles and responsibilities of community and secondary care paediatricians, and how these interface with primary care.

This leaves the problem of out of hours care. After the implementation of the GMS contract the move to out of hours centres to which parents and children travel will become more prevalent as more general practitioners opt out of out of hours care. It is essential that such units can provide safe assessment and care of acutely ill children. To that end such units will need to be staffed at all times by general practitioners with relevant child health training and most critically of all must have facilities for observation, perhaps by trained nurses for an hour or so, in order that the trajectory of illness can be adequately assessed. In fact secondary care paediatric services probably have a right to expect this level of service to limit the rising tide of admissions that has arisen, at least in part, for want of appropriate opportunities for assessment over time in the community.

The future is clear; it remains a general practice based service but with better and more formalised relationships with both community and hospital paediatric services.

\section{Who should provide primary care for children?}

\section{M Ni Bhrolchain}

"Primary health care is essential health care ... made universally accessible to individuals and families in the community ... It is the first level of contact of individuals ... with the national health system bringing health care as close as possible to where people live and work, and constitutes the first element of a continuing health care process".'

$\mathrm{T}$ raditionally, UK general practitioners (GPs) have provided primary care for all age groups. However, the Royal College of Paediatrics and Child Health (RCPCH) has recently proposed that paediatricians should take on primary care for children. This article assumes that this proposal includes all the elements of primary care paediatrics as seen in those countries where primary care paediatricians already practice: assessment and management of acute illness, ongoing management of chronic conditions including disability, and primary prevention including immunisation and "well child" visits. Does this proposal withstand scrutiny?

The increase in hospital admissions for acute illness appears to be due to primary care problems managed by secondary care doctors

There has been a significant increase in the number of children admitted to hospital for acute illness. ${ }^{2}$ Those who promote the concept of primary care paediatricians often cite poor primary care as the reason.

The evidence challenges this theory. Boyle et al showed that referrals from primary care to Derbyshire Children's Hospital showed no increase between 1994 and 1998. ${ }^{3}$ MacFaul et al found that admission in Yorkshire was more likely after self-referral to $\mathrm{A} \& \mathrm{E} .{ }^{4}$ Admission was also related to social disadvantage and presentation at night. In 1996, Dale et al showed that GPs were significantly more cost effective in dealing with primary care presentations to a London A\&E, when compared with senior house officers (SHOs) and registrars. ${ }^{5}$

The problem here therefore seems to be one of access on the one hand and secondary care doctors who are less skilled in managing primary care problems on the other. Inappropriate use of secondary care services is likely to be worse in city areas and where there is a children's hospital with a reputation for knowing about children. Parents' lack of experience in managing acute illness in
Arch Dis Child 2004;89:115-116. doi: 10.1136/adc.2003.040691

Correspondence to: $\operatorname{Dr} D$ Sowden, Nottingham Postgraduate Dean; david.sowden@ nottingham.ac.uk

\section{REFERENCES}

1 Wanless D. Securing our future health taking a long term view. Final report. London: HM Treasury, 2002

2 Department of Health. The NHS plan. A plan for investment. A plan for reform. London: Stationery Office, 2001

3 Department of Health. Delivering the NHS plan. Next steps on investment. Next steps on reform. London: Stationery Office, 2002.

4 Marsh G, Kaim-Candle P. Team care in general practice. London: Croom Helm, 1976.

5 Department of Health. Unfinished business. Proposals for reform of the SHO grade. London: Stationery Office, 2002.

6 Department of Health. Modernising medical careers. London: Stationery Office, 2003.

small children may also generate anxiety, fuelled by regular headlines about deaths from meningitis.

Solutions might include GPs in A\&E to manage primary care problems, training in primary care for specialist trainees, and redesigning services in ways that avoid admission, for example, hospital at home schemes run by nurses. ${ }^{67}$

\section{Community paediatricians have} until recently provided primary care services and may not be too keen to go back to it

Community paediatricians have spent the past decade extracting themselves from providing primary care. We have redesigned services to meet the increasing need for specialist care for children with non-acute conditions. We have been forerunners in supporting clinical nurse specialists (we call them health visitors and school nurses), improving access by referral protocols from screening and surveillance to manage demand and delegating to our specialists nurses those tasks that do not need medical training. With our primary care colleagues we have reduced or all but eliminated a number of fatal conditions through preventive programmes, and have ensured that all GP registrars have access to protected training in child health and development through the child health surveillance courses run for GP registrars.

The committed paediatricians who provided primary care in preceding decades had few career opportunities. They belonged neither to the paediatric "club" nor to general practice and lived largely in no man's land. Much of what they did has now been delegated to primary care nurses and allied health professionals (AHPs) or remains a secondary service within community paediatrics. 
Table 1 Training needs for each level of child health practitioner

\begin{tabular}{|c|c|c|}
\hline Training level & Training needs & Summative assessment \\
\hline Undergraduate & $\begin{array}{l}\text { An understanding of child health in the community, child development, the care pyramid, } \\
\text { managing common conditions, both in primary and secondary care }\end{array}$ & $M B$ \\
\hline $\mathrm{SHO}$ & $\begin{array}{l}\text { Consolidating knowledge of child health, managing common conditions, and exposure to } \\
\text { rare conditions under supervision }\end{array}$ & $\begin{array}{l}\text { DCH } \\
\text { MRCPCH (Part 1) }\end{array}$ \\
\hline $\begin{array}{l}\text { GP registrar/career } \\
\text { paediatric SHO }\end{array}$ & $\begin{array}{l}\text { Consolidating above, managing rare and long term conditions under supervision, } \\
\text { understanding the referral process, understanding preventive services for children, } \\
\text { understanding the role of specialist nurses and AHPs }\end{array}$ & $\begin{array}{l}\text { DCH } \\
\text { MRCPCH } \\
\text { MRCGP }\end{array}$ \\
\hline Specialist registrar & $\begin{array}{l}\text { Consolidating above, taking increasing responsibility for seeing unselected referrals } \\
\text { and managing complex conditions, understanding how to manage services }\end{array}$ & $\begin{array}{l}\text { CCST } \\
\text { MD }\end{array}$ \\
\hline GPwSI & $\begin{array}{l}\text { Consolidating knowledge of paediatrics in primary care, understanding the interface between } \\
\text { primary and secondary, taking a strategic role in children's services within the PCT, perhaps } \\
\text { contributing to non-acute paediatric services in hospital and/or community settings }\end{array}$ & $\begin{array}{l}\mathrm{DCH} \\
\mathrm{MSc}\end{array}$ \\
\hline $\begin{array}{l}\text { Consultant in the early } \\
\text { years }\end{array}$ & $\begin{array}{l}\text { Consolidating clinical knowledge, practising independently but with a senior colleague as } \\
\text { mentor, taking increasing responsibility for managing services, strategic role in area of special } \\
\text { interest }\end{array}$ & $\begin{array}{l}\text { MSc } \\
\text { Management qualification } \\
\text { Teaching qualification }\end{array}$ \\
\hline Established consultant & $\begin{array}{l}\text { Consolidating knowledge and expertise in management, clinical manager role, training role, } \\
\text { external roles in college or wider NHS }\end{array}$ & \\
\hline
\end{tabular}

Demand management techniques such as protocol driven investigation could significantly reduce outpatient referrals

About $2 \%$ of children are referred to general paediatricians in any year and this rate has not changed for the past decade. $^{8-10}$ The commonest conditions referred are heart murmurs, urinary tract infections, and constipation. ${ }^{10}$ Asthma-the single commonest condition referred in the 1988 study $y^{8}-$ no longer features in the top five. This suggests that GPs can successfully manage childhood conditions when supported to do so by clear guidelines. GP access to echocardiograms, renal ultrasound, and management protocols for constipation could reduce outpatient demand by $30 \%$, releasing paediatric time for other things. Progress on improving GP access to such investigations has been slow, with a tendency to expand secondary care services to meet demand rather than redesigning services. Yet, the yield from investigations requested by GPs has consistently been shown to be as good as the yield from those requested by specialists. ${ }^{11}$

There is some evidence that community paediatricians are experiencing increased demand and see more complex children. ${ }^{10}$ There may also be less opportunity to transfer care to GPs. While GPs are confident in managing some issues such as immunisation with advice, they are not confident in managing children with special needs without secondary care support (Mindlin M et al, unpublished data). ${ }^{12}$

\section{We need to train the next generation of primary and secondary care practitioners to meet the needs of children and families first}

Children and families need good access to appropriate services as close as possible to home or school. Primary care is the point of first access and the evidence suggests that primary care nurses and doctors do a good job: they manage about $90 \%$ of children presenting to them without referral, and GPs are consistent about what they wish to manage and what should go to secondary care (Mindlin $\mathrm{M}$ et al, unpublished data) for non-acute presentations at least. The pressure on secondary care services comes from patient demand, a need to control working hours and, in my view, a need to redesign and modernise services. I do not believe that paediatricians should take on the $90 \%$ of patient contacts now seen in primary care. I think we do need to consider which patients need secondary care services and which can be seen safely and more effectively in primary care. This may require us to challenge existing beliefs about how, where, and by whom services should be provided.

The training needs I perceive for each level of child health practitioner are outlined in Table 1. I have not presumed to comment on nurse or AHP training. The concept of GPs with a special interest (GPwSI) could foster links between primary and secondary care, as will community paediatricians' move into Primary Care Trusts (PCTs) alongside GPs. Hospital based paediatricians need to strengthen ties with primary care based on mutual respect for their different talents. It is unlikely that many GPwSIs could maintain their skills to contribute to acute hospital rotas. Community paediatricians are already finding this difficult and withdrawing from them, concerned about clinical governance issues.

Hospital paediatricians will need to find other solutions to maintain essential acute services for ill children who need them. Primary care paediatricians, in my view, are not it.
Arch Dis Child 2004:89:116-117. doi: 10.1136/adc.2003.040667

The author is an FRCPCH and MRCGP. She is currently developing training materials for primary care on child development topics with the RCGP but these are equally applicable to any group delivering primary care to children in the community.

Correspondence to: $\operatorname{Dr} C M N$ Ni Bhrolchain, Huntingdonshire PCT, Primrose Lane, Huntingdon PE29 IWG, UK;

Cliona_nib@lineone.net

\section{REFERENCES}

1 First International Conference on Primary Health Care. Alma Ata 1978

2 Royal College of Paediatrics and Child Health. The next ten years. Educating paediatricians for new roles in the 21 st century. London: $\mathrm{RCPCH}$, 2002.

3 Boyle R, Smith C, Mclntyre J. The changing utilization of a children's emergency department. Ambulatory Child Health 2000;6:39-43.

4 MacFaul R, Stewart M, Werneke U, et al. Parental and professional perception of need for emergency admission to hospital: prospective questionnaire based study. Arch Dis Child 1998;79:213-18.

5 Dale J, Lang H, Roberts JA, et al. Cost effectiveness of treating primary care patients in accident and emergency: a comparison between general practitioners, senior house officers, and registrars. BMJ 1996;312:1340-4.

6 Royal College of Paediatrics and Child Health. Old problems, new solutions. 21 st century children's healthcare. London: RCPCH, 2002.

7 Sartain SA, Maxwell MJ, Todd PJ, et al. Randomised controlled trial comparing an acute paediatric hospital at home scheme with conventional hospital care. Arch Dis Child 2002;87:371-5

$8 \mathrm{Ni}$ Bhrolchain CM. A district survey of paediatric outpatient referrals. Public Health 1992; 106:429-36.

9 MacFaul R, Long R. Paediatric outpatient utilisation in a district general hospital. Arch Dis Child 1992:67:1068-72.

10 Holmes NR, Ni Bhrolchain CM. Case mix presenting to paediatricians in a UK district (1998). Public Health 2002;116:179-83.

11 White PM, Halliday-Pegg JC, Collie DA. Open access neuroimaging for general practitionersdiagnostic yield and influence on patient management. Br J Gen Pract 2002;52:33-5

12 Ni Bhrolchain CM, Klein LE, Smith MJ. Children with disabilities and the Children Act: who will assess their needs? Public Health 1993; 107:101-6 
Primary care paediatrics and child health

\section{Nurse practitioners}

\section{S Hall, C Lawson}

\section{Role in acute paediatric care}

$\mathrm{T}$ his paper proposes that community based nurse practitioners are well placed to provide care to acutely ill children. The data provided from a nurse led primary care service in Newcastle upon Tyne illustrate that $98 \%$ of children presenting with everyday complaints are effectively treated by a nurse practitioner.

The role of the nurse practitioner in primary care, although innovative, can present challenges to historical practices in the National Health Service. Nevertheless the movement away from conventional roles and service delivery is a strategy that is recommended by current health service reform and policy. ${ }^{1}$

One such reform is the notion that experienced nursing staff can relieve doctors of certain tasks, which according to Pearce, ${ }^{2}$ are tasks the medical profession have been doing for many years, that other suitably trained staff could undertake, for example, clinically assessing patients and requesting $x$ ray examinations.

Step forward the nurse practitioner! Nurse practitioners are experienced nurses who, after extensive training, are proficient in certain competencies such as consultation skills, physical examination skills, and clinical diagnosis. Equipped with these skills they are able to accept responsibility and accountability for the assessment, diagnosis, and implementation of a range of care interventions for patients who present to them with undifferentiated medical conditions. ${ }^{3}$

Most nurse practitioners have an Extended Nurse Prescribing qualification, which permits them to prescribe drugs and therapeutics for specific conditions. They are also able, with the consent of the patient/carer, to negotiate care packages, which may include commencement of investigations, liaison with multiple agencies, and onward referral to different care providers.

To sustain them in this challenging role the Royal College of Nursing advocates that nurse practitioners should have access to a comprehensive training package and ongoing education based on clinical/nursing competencies. This they propose will enable them to be competent, autonomous, and ultimately safe practitioners. ${ }^{4}$

So can the nurse practitioner provide safe, effective care to acutely ill children? Our evidence confirms that, in the majority of cases, the answer is yes.

We have developed an entirely nurse led primary care service to a deprived inner city population in Newcastle upon Tyne (approx 10000 ) which has been open to the public since May 2002 and offers an appointment/walk-in service on a daily basis.

This generic service has evolved with the support of the local community, Newcastle Primary Care Trust, and local general practitioners. Our aim is to provide a holistic service to the local population by offering a range of services, which include, for example, undertaking cervical smears, blood tests, childhood immunisations, and advice and support for people who want to stop smoking.

It is our experience that this holistic approach is realised; for example, the father who attends with his asthmatic child is encouraged to share any concerns he may have about his own health. These can then be addressed within this contact or he will be actively encouraged to access the service again.

Although this nurse practitioner service is available to children, parents, individuals, and their extended families, paediatric consultations form the vast majority of our work, accounting for almost two thirds of all contacts (954 of 1515, May 2002-03).

The statistics relating to acute paediatric consultations illustrate that the total number of 0-16 year olds seen between May 2002 and May 2003 was 954; of these, 744 were $0-5$ year olds. The commonest paediatric presentations were for skin conditions (23\%), vaccinations $(16 \%)$, ear nose and throat (14\%), and respiratory conditions (10\%). A total of 291 drugs were dispensed/prescribed within these 744 consultations (39\%). These were predominantly for analgesics (11\%), antibiotics (11\%), and emollients (4\%).

Further analysis of the $0-5$ year olds data reveals that between May 2001 and May 2002, 59\% of children, after clinical assessment, were offered "advice only". A further 39\% received treatment; $1 \%$ were referred to their own GP and a further $1 \%$ to paediatric secondary care.

The data show nurse practitioners can be seen as key care providers for children presenting with acute conditions in a primary care setting, as most conditions are self limiting and do not require any medical intervention. What the data do not illustrate is that as primary care nurse practitioners we also possess considerable knowledge of the determinants of health within our local community. This makes it possible for us to support the child and family beyond issues related entirely to the treatment of their presenting complaints.

To illustrate, one example from our practice was the many children who presented to our service with impetigo. It transpired that many of the affected children attended the same school nearby and there were no overt hand washing/hygiene practices in place. Having regular contact with local parents enabled us to discuss infection pathways and possible solutions with those concerned in a sensitive way to resolve the situation.

Comprehensive audit trails reveal that we are providing an effective, safe, primary care service while adhering to our Scope of Professional Practice. ${ }^{5}$ We have also sought the views of service users and the data confirm that nurse practitioners can provide a range of health care services for children that are acceptable to their parents/carers and that parents/carers attach high value to the fact that the service is an easily accessible point of contact.

Parents/carers inform us that they do not want unnecessary contact with their GP or lengthy waits in accident and emergency departments-services which can be miles away from their homesfor their children to receive treatment for minor ailments and minor injuries that often require advice only or simple treatments. Nurse practitioners can provide this level of care and can, after clinical assessment of the child, determine when a more specialised paediatric opinion is required.

There are many good reasons for introducing the nurse practitioner role in different settings and each must identify its own. The value of our nurse practitioner service is that it is a convenient, safe, effective health care 
provision for children presenting with acute illnesses.

Arch Dis Child 2004;89:118-119.

doi: 10.1136/adc.2003.043216

.................

Authors' affiliations

S Hall, C Lawson, Newcastle Primary Care Trust, UK
Correspondence to: S Hall, Nurse Practitioner, Newcastle Primary Care Trust, UK; admin@lemingtonclinic.fsnet.co.uk

\section{REFERENCES}

1 Coulter A. Shifting the balance from secondary to primary care. BMJ 1995;311:1447.
2 Pearce L. Handing over. Nursing Standard 2003;17(22): 14

3 United Kingdom Central Council for Nursing, Midwifery and Health Visiting. Standards for education and practice. London: UKCC, 1994

4 Royal College of Nursing. Statement on the role and scope of nurse practitioner practice. London: Royal College of Nursing, 1996.

5 National Midwifery Council. Scope of professional practice. National Midwifery Council, 2002.
Primary care paediatrics and child health

\section{The future of paediatric primary care and child health}

S Court

\section{Child care teams are well placed to deliver needs led primary care paediatrics}

$\mathrm{T}$ he central objective of paediatric primary care (PPC) should be the integration of preventative and curative health services. Delivering this objective will not be simple or the same in different health districts, but it would achieve a level of primacy if managerially it was the responsibility of the Primary Care Trust (PCT). In my opinion there should no longer be any distinction between the community paediatrician and the conventional DGH based generalist. Both need to be confident working in hospital and community; in order to understand chronic illness clinicians need to have a familiarity with home, community, and school. We need evidence based pathways of care so that a child's need is met by the most appropriate health professional in a convenient child friendly environment and where the outcome reflects the quality of decision making at each stage. Much "secondary" care previously undertaken in hospitals is now undertaken by general practitioners, specialist nurses, and consultants in the community. The boundaries of ambulatory primary/secondary care are becoming increasingly blurred.

In 1976 the role of a general practitioner paediatrician was described but found little favour. ${ }^{2}$ Even so in many practices now, certain partners are assuming a greater responsibility for children, and are recognised by parents as the children's doctor. Within Newcastle upon Tyne (with 40 practices distributed between three localities), there are practitioners who have a declared paediatric interest. Within localities these primary care paediatricians (PCPs) should be part of multidisciplinary Locality Child Care Teams. Team members should include.

- PCPs

- Clinical medical officer/staff grade/ associate specialist

- $\mathrm{SHO}(\mathrm{s})$

- Registrar(s)

- The consultant(s)

- Dietician

- Paediatric nurse practitioner (PNP)

- Community paediatric nurse (CpaedN)

- School health advisers (SHA)

- Health visitor(s) (HV)

- Physiotherapists, speech therapists, and occupational therapists

- Education welfare officer (EWO)

- Social worker (SW)

- Police

- Named child protection personnel

- Psychologist

- Pharmacists.

Any service has to be needs driven and delivered by a team with complimentary skills. Each locality has its particular mix of social and clinical challenges. If practical, teams should work from children's day care centres (CDCCs) $)^{3}$ or polyclinic within the locality. The following would be the responsibility of locality child care teams:

- Public health of all children in the locality (to include health promotion/ accident prevention/immunisation)
- Initial diagnosis and investigation of children with developmental delay

- Recognition and management of child protection (CP)

- Initial management of acute illness and uncomplicated chronic illness.

- Management of growth problems

- Responsibility for looked after children and adoption medical service

- School health.

Of necessity the service will be delivered in different sites (home, school, CDCC) by members of "functional teams" drawn from the above list of professionals. Examples of locality functional teams might include:

- Behaviour/mental health (ADHD, autism, truancy, bullying)

- Child protection (parenting, sleep and crying management, social exclusion/LAC/adoption)

- Disability

- Nutrition

- Illness (acute, chronic).

Co-location of core staff within functional teams is important, perhaps particularly for child protection (teams will include SW, police, EWO, and named CP health professionals). Extending the model of community based management of growth faltering, ${ }^{4}$ the "functional nutrition team" would include consultant plus trainee, dietician, HV, CpaedN, PCP, SHA, SW, and behaviouralist. This would allow the team to encompass breast feeding, weaning, healthy eating, healthy schools, height screening, constipation prevention, eating disorders, obesity prevention, and gastrostomy care. A constipation service, for example, requires an initial "medical" review; with frequent contact by CpaedNs providing necessary support. Attendance at a consultant or PCP clinic can be minimised by scheduled notes review of the locality case load by all involved practitioners, identifying patients needing an appointment. This model of empowered nursing plus joint medical review could be applied to other chronic illness, reducing clinic review in hospital for children who remain well, for example, asthmatics or epileptics. 
Members of the "functional illness team", particularly community based generalist trainees together with their consultants, could "in reach" into local hospitals by rotation. Much acute work is/could be dealt with by junior paediatric staff $f^{5}$ and PNPs. The day to day running of the acute unit (A\&E, day ward, short stay unit) would be undertaken by PNPs, ${ }^{6}$ together with registrar/ staff grade doctors, overseen by the consultants who would have both hospital and community responsibilities. The "acute" pathway of care starts with parents, some using NHS Direct, and ends with a consultant; triage remains an essential element undertaken by PCPs or PNPs. In the community, consultants would work alongside PCPs and other members of the illness team (PNPs, CpaedNs) undertaking clinics within a locality CDCC, covering general referrals (for example, headache, abdominal pain, growth problems, enuresis, constipation, asthma, behaviour and development problems, fits and "funny turns", or possible congenital anomalies). In progressing along the care pathway it should only be necessary to see a tertiary specialist once accepted thresholds for onward referral have been reached.
Until recently children were not seen as politically important; the climate is now changing. The government, in the recent green paper, ${ }^{7}$ identifies accountability as a priority. If health professionals are to be accountable, they need appropriate training to meet defined responsibilities; outcomes should be audited and training updated.

We know that a sizable minority of GPs receive little further postgraduate training. If the generalists of tomorrow are to work in managed networks and multiple small focused teams, trainees need to be exposed to this model from the start.

Child care teams that include general paediatricians, paediatric nurse practitioners, primary care paediatricians, as well as other disciplines are well placed to deliver needs led primary care paediatrics working from a locality base. Some members will "in reach" into the local hospital unit undertaking secondary care. Training should be largely community based. Pathways of care should be followed, with referral to tertiary services only when accepted thresholds have been reached.

Despite our best efforts hospitals remain frightening, unfamiliar, and at times dangerous places for children. In the broad context of childhood illness, only in a small percentage of cases are hospitals the necessary forum for care. Most childhood illness is or should be dealt with outside hospital. The essence of this proposal has been reviewed in Strengthening the care of children in the community. ${ }^{1}$

Arch Dis Child 2004;89:119-120.

doi: 10.1136/adc.2003.040659

Correspondence to: $\operatorname{Dr} \mathrm{S}$ Court, Community Paediatric Department, Newcastle General Hospital, Westgate Road, Newcastle upon Tyne NE4 6BE, UK; Simon.court@ncl.ac.uk

\section{REFERENCES}

1 Royal College of Paediatrics and Child Health Strengthening the care of children in the community: a review of community child health in 2001. London: Royal College of Paediatrics and Child Health, 2001

2 Court SDM. Fit for the future. Report of the Committee on Child Health Services. London: HMSO, 1976.

3 Taylor B. How many in patient paediatric units do we need? Arch Dis Child 1994;71:360-4.

4 Wright CM. Identification and management of failure to thrive: a community perspective. Arch Dis Child 2000;82:5-9.

5 Armon K, Stephenson T, Gabriel V, et al. Determining the common medical presenting problems to an accident and emergency department. Arch Dis Child 2001;84:390-2.

6 Royal College of Nursing. Nurse practitioners: a draft $R C N$ guide to the nurse practitioners role, competencies and programme of accreditation. London: Royal College of Nursing, 2003.

7 Green paper. Every child matters. London: The Stationery Office, September 2003. 